\title{
Psicologia Escolar na rede pública de educação dos Municípios de Santa Catarina
}

\author{
Celso Francisco Tondin \\ Débora Dedonatti \\ Irme Salete Bonamigo
}

\begin{abstract}
Resumo
Este artigo foi elaborado a partir da pesquisa que mapeou os projetos de lei que inserem os psicólogos na rede pública de Educação nos municípios catarinenses. O objetivo é discutir as concepções de Psicologia Escolar presentes nos projetos de lei, visando compreender em que medida apresentam elementos inovadores e pertinentes às discussões recentes na área de Psicologia Escolar e Educacional. Os dados foram produzidos por meio de entrevistas realizadas por telefone com secretários(as) de educação de municípios que possuem psicólogo na Educação e consultas aos projetos de lei. Constatou-se que a legislação contempla uma variedade de concepções teóricas (tradicionais e contemporâneas), as quais repercutem diretamente nas formas de atuação e nos resultados dos trabalhos dos psicólogos, divergindo de acordo com o grau de criticidade de cada profissional e o contexto de atuação.
\end{abstract}

Palavras-chave: Psicologia escolar, leis, atuação do psicólogo.

\section{School Psychology in Santa Catarina's public education}

\begin{abstract}
This article results from a study that mapped the law projects through which psychologists were included in Santa Catarina's public school system. We aim at discussing the conceptions of School Psychology visible in the law projects, seeking to understand to what extent they present innovative and pertinent elements to the recent discussions in the area of School and Educational Psychology. The data were produced through interviews by telephone with secretaries of Education of the cities that employ psychologists. It was evidenced that the legislation contemplates a variety of theoretical conceptions (traditional and contemporaries), which are perceptible in psychologists' performance and works. The results vary according to the degree of criticism of each professional and the context of his or her work.
\end{abstract}

Keywords: School psychology, laws, psychologist performance.

\section{Psicología Escolar en la red pública de educación de los Municipios de Santa Catarina}

\section{Resumen}

Este artículo se elaboró a partir de investigación que mapeó los proyectos de ley que insieren los psicólogos en la red pública de Educación en los municipios de Santa Cataria. El objetivo es discutir las concepciones de Psicología Escolar presentes en los proyectos de ley, en el intento de comprender en que medida presentan elementos innovadores y pertinentes a las discusiones recientes en el área de Psicología Escolar y Educacional. Los datos se produjeron por medio de entrevistas realizadas por teléfono con secretarios(as) de educación de municipios que poseen psicólogo en la Educación y consultas a los proyectos de ley. Se constató que la legislación contempla una variedad de concepciones teóricas (tradicionales y contemporáneas), las cuales repercuten directamente en las formas de actuación y en los resultados de los trabajos de los psicólogos, divergiendo de acuerdo con el grado de crítica de cada profesional y el contexto de actuación.

Palabras clave: Psicología escolar, leyes, actuación del psicólogo. 


\section{Introdução}

Este artigo tem como pano de fundo a pesquisa "A atuação do psicólogo frente à demanda escolar: regulamentação, concepções, práticas e inovações", a qual tem sido desenvolvida em âmbito nacional, envolvendo os estados de São Paulo, Minas Gerais, Bahia, Acre, Rondônia, Paraná e Santa Catarina, coordenada pelo Laboratório Interinstitucional de Estudos e Pesquisas em Psicologia Escolar (LIEPPE), do Instituto de Psicologia da Universidade de São Paulo, com apoio do CNPq. Os dados aqui apresentados referem-se a uma pesquisa associada a esta de longa duração, intitulada "Mapeamento dos projetos de lei que inserem os psicólogos na rede pública de Educação dos municípios de Santa Catarina", realizada apenas no estado de Santa Catarina com apoio do Fundo de Amparo à Pesquisa da Universidade Comunitária Regional de Chapecó (Unochapecó) e do Artigo 170 da Constituição do Estado de Santa Catarina.

Pretende analisar, através dos resultados da pesquisa em questão, as concepções de Psicologia Escolar presentes nos referidos projetos de lei, avaliando de que forma estas concepções têm norteado as práticas que a Psicologia desenvolve no contexto escolar e educacional, buscando compreender se as mesmas acompanham os avanços da ciência e da profissão, no que se refere ao grau de criticidade.

A relevância deste tema justifica-se quando analisamos retrospectivamente como a Psicologia atuou ao longo da história no campo da Educação, sendo possível compreender as influências que permeiam as práticas realizadas neste contexto, atualmente.

Entende-se a Psicologia Escolar como área de estudo e atuação, cujo foco reside sobre o contexto educacional (escolar ou extra-escolar) e na revisão crítica dos conhecimentos acumulados, tanto pela Psicologia com ciência, quanto pela Pedagogia e pela Filosofia da Educação. Sendo assim, o trabalho do psicólogo escolar é definido pelo seu compromisso teórico e prático com as questões escolares e educacionais, independente do seu local de trabalho (Meira \& Antunes, 2003).

Retomando brevemente alguns aspectos históricos, pode-se afirmar que o surgimento da Psicologia Escolar esteve diretamente relacionado à psicometria e especialmente à aplicação de testes psicológicos. Os primeiros trabalhos desempenhados por psicólogos nos sistemas de ensino, no Brasil, a partir do final do século XIX, foram de medir habilidades e classificar crianças quanto à capacidade de aprender, resumindo suas atividades à aplicação de testes de inteligência e de prontidão para a aprendizagem ou a realização de diagnósticos psicológicos. Em níveis mais sofisticados, alguns profissionais faziam terapia na escola, avaliação psicológica através de testes e, outros, dedicavamse a programas preventivos, atuando com pais, professores e administradores, respaldados por uma concepção adaptacionista de saúde mental (Patto, 1987).

Nesse sentido, pode-se dizer que a Psicologia Escolar surge marcada por modos de pensar descontextualizados, na medida em que não considera os determinantes sociais do fenômeno humano, preocupando-se exclusivamente com padrões gerais de comportamento estabelecidos estatisticamente (Yazlle, 1997). Em outras palavras, aponta-se a "ausência de compromisso da Psicologia com a condição multideterminada das circunstâncias nas quais os indivíduos se humanizam" (Tanamachi \& Meira, 2003). Trata-se assim, de uma Psicologia comprometida com a ordem e o controle, ou seja, com as regras sociais decorrentes do sistema dominante - o capitalismo (Yazlle, 1997).

No início do século XX, observa-se a introdução do modelo clínico na Psicologia Escolar, inspirado na medicina, cujo objetivo era diagnosticar e tratar crianças que apresentassem problemas de aprendizagem (Lima, 2005). Assim, enquanto alguns profissionais utilizavam procedimentos psicotécnicos, advindos de laboratórios experimentais, baseados em testes de inteligência e técnicas projetivas de personalidade, outro grupo de psicólogos realizava atendimento psicoterapêutico, individualizado, detendo-se, sobretudo, à investigação de problemas situados nos alunos (psicológicos, neurológicos, fonoaudiológicos, psiquiátricos), percebendo suas características pessoais como incompatíveis com a aprendizagem e o ajustamento escolar (Patto, 1987).

Nesta lógica, era desconsiderada toda a dimensão social do ensino, desde a dinâmica institucional, a relação professor-aluno, os métodos e conteúdos de ensino, entre outros aspectos, os quais não eram objeto de questionamentos, nem mesmo enquanto variáveis que poderiam gerar problemas de ajustamento e/ou de aprendizagem. Somente anos mais tarde esse serviço foi reestruturado em outras bases, abandonando a linha de atendimento essencialmente clínica, tendo em vista a crescente demanda de diagnóstico e tratamento de crianças com problemas de aprendizagem (Patto, 1987).

Surge também, paralelo ao Movimento de Higiene Mental, um modelo de atendimento preventivo, focando ações de orientação, assistência, pesquisa e ensino em desajustamento infantil. Esse movimento acreditava que o psicólogo deveria se adiantar aos problemas e cuidar do bem estar individual e social (Lima, 2005).

A partir da década de 1980, essa visão tradicional da Psicologia na Educação passou a ser denunciada, iniciandose uma discussão crítica em relação à identidade e à função do psicólogo escolar. Respaldado, principalmente, pelo texto de Maria Helena Souza Patto ${ }^{1}$, o movimento da crítica buscou a inclusão dos processos desenvolvidos na instituição escolar na análise das dificuldades de aprendizagem. Nesse sentido, os problemas de aprendizagem passam a ser percebidos como um fenômeno complexo, socialmente constituído e que deve ser analisado em seus aspectos históricos, econômicos, políticos e sociais (Lima, 2005).

Com base nos pressupostos teóricos do Materialismo Histórico-Dialético, elaborado por Karl Marx, a concepção crítica entende o homem como um ser que tem nas relações sociais a possibilidade de se constituir juntamente com outros

1 Patto, M. H. S. (1987). Psicologia e ideologia: uma introdução crítica à psicologia escolar. São Paulo: T. A. Queiroz. 
homens, na medida em que se constroem formas de satisfação de suas necessidades, numa relação dialética. Dessa forma, os aspectos psicológicos devem ser compreendidos em seu caráter fundamentalmente histórico e social (Meira \& Antunes, 2003).

Portanto, pode-se dizer que o objeto de estudo e atuação da Psicologia Escolar é o encontro entre o sujeito humano e a educação, não focando nem o sujeito psicológico e nem o contexto educacional isoladamente, mas procurando compreender as relações que se estabelecem entre estes processos. A função do psicólogo escolar não é a resolução de problemas, nem a simples divulgação de teorias e conhecimentos psicológicos, mas de acordo com suas limitações, auxiliar a escola a eliminar os obstáculos que se colocam entre os sujeitos e o conhecimento (Meira \& Antunes, 2003).

\section{Metodologia}

Esta pesquisa tem caráter qualitativo, ou seja, "é orientada para a análise de casos concretos em sua particularidade temporal e local, partindo das expressões e atividades das pessoas em seus contextos locais" (Flick, 2004, p. 28). As técnicas de pesquisa utilizadas foram a entrevista por telefone com secretários(as) de educação de municípios que possuem psicólogo na Educação e a pesquisa documental em arquivos públicos, por meio de consultas aos projetos de lei dos municípios de Santa Catarina que inserem os psicólogos na rede pública de Educação.

Inicialmente, a pesquisa contou com dados do Relatório do Levantamento Sobre Projetos de Lei e Práticas de Psicólogos na Área de Educação, realizado pelo Conselho Regional de Psicologia de Santa Catarina (CRP-12, 2007), cujos resultados contribuíram com informações sobre 80 municípios do Estado. Cabe ressaltar que a pesquisa envolveu apenas as redes municipais de Educação porque a rede estadual não conta com psicólogos em seu quadro funcional.

Posteriormente, o trabalho de campo se desenvolveu por intermédio da Federação Catarinense de Municípios (FECAM), através da qual foram abordadas as 21 associações microrregionais de municípios que a compõe, por meio de entrevistas por telefone. Primeiramente, foram mapeados os municípios catarinenses que possuem psicólogos atuando na rede pública de Educação. Nesta etapa, foi necessário contatar mais de uma pessoa, a fim de obter os dados solicitados, devido à falta de informações de alguns profissionais e incompatibilidade entre os dados coletados.

Nos municípios onde foi constatada a presença de psicólogo atuando na educação, procurou-se verificar, com os Secretários de Educação, a existência de legislação que regulamentasse a atuação deste profissional no contexto escolar. Neste mesmo contato, nos municípios que possuem lei, investigou-se o número da mesma e as formas de acesso a estes textos.

O acesso a esta legislação se desenvolveu por meio de pesquisa aos endereços eletrônicos (sites) e via correio ou fax, ficando a critério de cada município a forma de en- caminhamento desta documentação, o que era combinado a partir do contato telefônico. Munidos destes documentos, passou-se para a etapa seguinte, cujo objetivo era analisar os conteúdos destes projetos de lei, a fim de verificar se os mesmos acompanham os avanços da ciência e da profissão, no que diz respeito à Psicologia Escolar crítica. Nesta etapa, optou-se por categorizar os conteúdos contidos nas leis, com o intuito de classificá-los e agrupá-los de acordo com os objetivos da pesquisa. As categorias elaboradas compreendem os seguintes itens:

1) provimento do cargo, que se refere ao preenchimento permanente ou temporário de lugar público;

2) grupos profissionais, entendido como a classificação dada ao conjunto de cargos, agrupados de acordo com a natureza da atividade;

3) Jornada de trabalho, que se refere ao número de horas trabalhadas semanalmente;

4) data de aprovação da lei, na qual é apresentado o dia, mês e ano de aprovação da lei e;

5) especificações do cargo, que se caracteriza pela descrição das atribuições, deveres e responsabilidades do cargo a ser provido.

No total, foram pesquisados 177 dos 293 municípios catarinenses. Destes, 27 possuem psicólogo na educação e apenas 12 possuem lei que regulamenta a atuação deste profissional.

Esta amostragem, que consideramos significativa, não foi definida previamente, mas é decorrente da dificuldade de englobar todos os municípios do Estado, em função do não retorno das informações por uma parcela deles e o tempo que seria exigido para cumprimento pleno desta etapa, o qual não dispúnhamos. Posteriormente, foram apresentados e analisados os dados com base nas categorias acima descritas, visando atender os objetivos da pesquisa. A análise do conteúdo expresso nesta legislação, procurou identificar as concepções que os embasam, verificando se as mesmas correspondem aos avanços da Psicologia Escolar crítica.

$\mathrm{Na}$ análise dos resultados foram considerados apenas 10 municípios, em função dos mesmos possuírem legislação que regulamenta a atuação do psicólogo escolar. Considerando que obtivemos um total de 12 municípios que possuem lei, cabe esclarecer que não foi possível acessar os dados de dois dos municípios no prazo pretendido.

\section{Apresentação e discussão dos resultados}

Os resultados da pesquisa em questão trouxeram dados importantes para as discussões que se têm dado no âmbito da Psicologia Escolar crítica, sendo eles quantitativos e qualitativos. A seguir, procura-se apresentar alguns resultados e desenvolver uma análise sobre os projetos de lei e as práticas desenvolvidas pelo psicólogo escolar, atualmente.

Dos 177 municípios pesquisados, no que se refere à existência de psicólogo atuando na Educação, constatou- 
se que 27 municípios possuem psicólogo na Educação, 76 municípios possuem psicólogo na Saúde que presta serviço para a Educação e 74 municípios não possuem psicólogo na Educação. Destes 27 municípios que possuem psicólogo na Educação, quanto à existência de legislação que regulamenta a atuação deste profissional, obtiveram-se os seguintes resultados: 12 municípios possuem lei que insere o psicólogo no quadro de funcionários da educação, 14 municípios não possuem lei e um município não foi possível obter esse dado devido à dificuldade de contatá-los.

No que se refere aos projetos de lei, especialmente ao provimento do cargo de psicólogo escolar, verificou-se que, em sua maioria, o psicólogo compõe o quadro de funcionários permanentes da Educação, sendo o caso de 7 dos 10 municípios pesquisados. Entre os demais, um compõe o quadro de funcionários temporários da Educação e 2 fazem parte do quadro geral de funcionários efetivos no município, embora atuem na Educação. Quanto à carga horária de atuação profissional, verifica-se uma variação de 20 a 44 horas semanais.

Identificaram-se, na análise da legislação, alguns grupos profissionais, ou seja, um conjunto de cargos agrupados de acordo com a natureza da atividade, que inclui a função de psicólogo escolar. Dentre a variedade de termos utilizados para designá-los, destacam-se: "grupo ocupacional profissional", "grupo de apoio técnico científico", "grupo de especialistas em assuntos educacionais" e "suporte pedagógico direto à docência".

Cabe destacar que esses termos diferem também quanto ao seu conteúdo, isto é, aos grupos profissionais integrantes. O termo mais comumente utilizado e que merece mais atenção é o "grupo de especialistas em assuntos educacionais", sendo identificado em 3 projetos de lei. No entanto, o mesmo termo designa um grupo diferente de profissionais nestes projetos, por exemplo, em determinada lei engloba os cargos de "psicólogo escolar", "supervisor escolar" e "orientador educacional”, já em outra, além destes, compreende os cargos de "fonoaudiólogo" e "auxiliar de ensino da Educação Infantil”.

A denominação "especialista em assuntos educacionais" nos remete a pensar a questão das especialidades ou especialismos. Hüning e Guareschi (2005) ressaltam que as delimitações do conhecimento vão criando campos de competências, dispositivos de inteligibilidade, especialidades e especialistas. Essas concepções trazem alguns perigos para as ciências, especialmente para a Psicologia, no que diz respeito ao risco de fragmentação do ser humano, da privatização das diferentes instâncias da vida, sendo que as especialidades podem prestar-se mais a uma questão competitiva do que a um suposto aprimoramento dos cuidados com a saúde ou com a vida.

Considerando que a contemporaneidade nos apresenta a inviabilidade de pensar o conhecimento ou a prática profissional dentro de fronteiras nitidamente delimitadas, cabe-nos perguntar se a denominação "especialista em assuntos educacionais" contida nos projetos de lei concebe o trabalho da Psicologia enquanto uma especialidade ou se está relacionada às novas propostas de construção do conhecimento, levando em conta a diluição das fronteiras, de tempos, espaços e saberes. Compreender essa concepção contida nos projetos de lei nos remete às expectativas do serviço público quanto ao trabalho do psicólogo escolar, bem como as práticas que estão sendo efetivamente realizadas nas instituições escolares.

Enfatizando a emergência das leis, nos municípios nos quais foi identificada a existência das mesmas, constatou-se que sua aprovação data de um período recente, compreendendo a última década, mais especificamente o período de 1999 a 2007.

Considerando o período de envolvimento da Psicologia com as questões da Educação, que teve início no final do século XIX, período no qual se evidenciou a incorporação dos saberes psicológicos às questões educacionais, e que a profissão do psicólogo foi constituída legalmente em 1962, acredita-se que a regulamentação da atuação do psicólogo escolar nos municípios catarinenses, tendo ocorrido somente no final do século $X X$, foi um tanto tardia.

Antunes (2003) ressalta que, a partir de 1962, as relações entre Psicologia e Educação tornaram-se alvo de polêmicas, em função das críticas que passaram a emergir. Nesta época, a Psicologia estava incorporada à prática pedagógica e a atuação profissional dos educadores, muitas vezes desempenhando práticas marcadas por insuficiente fundamentação teórica. Ao mesmo tempo, a prática específica do profissional psicólogo na escola estava muito embasada em uma perspectiva clínica, atuando no atendimento individual de "crianças com problemas de aprendizagem", fora da sala de aula.

Em meados de 1970, a utilização de testes passa a ser duramente criticada. Essas críticas partem da maneira como os testes eram utilizados e suas conseqüências para o educando, levando em conta que os resultados dos testes eram usualmente interpretados como atribuições próprias do sujeito, culpabilizando o aluno pelos ditos "problemas de aprendizagem". Essa concepção negligenciava as condições socioculturais e pedagógicas, além de causar danos nocivos para um grande número de crianças, que eram encaminhadas às classes especiais (Antunes, 2003).

Além disso, as críticas estendiam-se às interpretações e ações reducionistas, cujas determinações dos problemas escolares eram buscadas em fatores externos ao ambiente escolar, como: desenvolvimento mental, atenção, comprometimentos motores ou emocionais (entendidos como produto das relações familiares). Isso resultava em um problema ainda mais grave, o encobrimento dos determinantes intraescolares, os quais eram responsáveis por grande parte dos problemas (Antunes, 2003).

Diante disso, analisa-se se que estas críticas, juntamente com a regulamentação da atuação do psicólogo escolar legitimaram o trabalho deste profissional, permitindo o desenvolvimento de um novo olhar sobre os problemas escolares, partindo de uma perspectiva crítica, que considera o ambiente escolar, bem como as práticas pedagógicas enquanto co-responsáveis pelos processos de aprendizagem. 
No que diz respeito às especificações do cargo de psicólogo escolar, ou seja, à descrição das atribuições, deveres e responsabilidades do cargo, foi verificado que: existem atividades generalistas no bojo dos projetos de lei, coexistem concepções distintas de Psicologia Escolar e inexiste especificação do cargo em alguns projetos de lei.

Desse modo, pode-se perceber que embora a lei vise regulamentar e legitimar o trabalho do psicólogo na escola aponta um número relativamente maior de atribuições da Psicologia, ou seja, atividades que a Psicologia pode desenvolver em diversos contextos, ao invés de serem enfatizadas as atividades específicas da Psicologia Escolar. Da mesma forma, a maior parte das atividades consideradas específicas pela legislação, podem ser desenvolvidas também por outros profissionais, o que demonstra certa negligência e/ou desconhecimento, por parte daqueles que participam da elaboração das leis, das especificidades da Psicologia Escolar.

Conforme afirma Meira (2003), ao mesmo tempo em que a Psicologia não pode desconsiderar a dimensão educativa em qualquer de suas áreas de atuação, a Psicologia Escolar não pode ser compreendida enquanto uma especialidade na formação do psicólogo, embora tenha especificidades, as quais precisam ser de conhecimento do profissional psicólogo que atua na escola.

A existência de atividades generalistas no bojo dos projetos de lei traz vantagens e desvantagens para a prática do psicólogo escolar. De um lado, percebe-se a generalização dessas atividades como uma alternativa que amplia as perspectivas de trabalho, levando em conta que estas podem ser desenvolvidas por vários profissionais, podendo atingir os mesmos objetivos a partir de referenciais teórico-práticos distintos. Por outro lado, a generalização dessas atividades pode resultar em um descuido com as especificidades da Educação, as quais devem ser do conhecimento dos profissionais que se propõem a desenvolver trabalhos no ambiente escolar. Quanto a essa questão, Tanamachi e Meira (2003) afirmam que o psicólogo precisa se colocar dentro da educação e assumir um compromisso teórico e prático com as questões da escola.

Cabe destacar que algumas leis que inserem o psicólogo na Educação não contemplam a especificação do cargo, o que nos leva a questionar as formas como são elaborados estes projetos de lei, quem participa desta elaboração e qual o envolvimento do psicólogo neste processo, tendo em vista que essa legislação regulamenta a sua atuação. Por acreditar que este profissional possua conhecimentos específicos do campo da Educação, bem como dos avanços da Psicologia Escolar crítica, considera-se sua participação fundamental na elaboração de projetos de lei, com o objetivo de ampliar e especificar as atividades que podem ser desenvolvidas em Psicologia Escolar e Educacional.

A ausência de especificação do cargo, ao mesmo tempo em que dá liberdade para a atuação do psicólogo escolar, não colocando limites quanto aos recursos utilizados nem às atividades que podem ser desenvolvidas, bem como às formas de condução destes trabalhos, também abre inúmeras possibilidades, permitindo o exercício de atividades que abarcam uma diversidade de concepções teóricas ou até mesmo a ausência de concepção teórica. Isso resulta muitas vezes em trabalhos insuficientes, que não atingem as expectativas da escola e reforçam os problemas que permeiam as práticas educativas.

Por outro lado, com relação às leis que apontam as especificações do cargo, nos propomos a verificar se as mesmas condizem com as atuais concepções de Psicologia Escolar crítica.

Com esse intuito, parece importante resgatar brevemente as concepções tradicionais em Psicologia Escolar, que são as seguintes: 1) teoria do dom ou das aptidões Individuais ("criança anormal"), que se utiliza de testes de aptidão e personalidade e acredita que a origem do problema está no indivíduo, em seus determinantes hereditários; 2) ambientalismo ("criança problema"), que parte da análise da história de vida e dos comportamentos e acredita que o problema escolar tem origem no ambiente familiar desajustado e/ou na criança e seus relacionamentos; 3 ) organicismo ("criança com distúrbio de aprendizagem"), utiliza-se de exame neurológico e eletroencefalograma, acreditando que o problema parte de uma disfunção cerebral, ou seja, de fatores orgânicos; 4) interacionismo ("criança carente, deficiente ou diferente"), utiliza-se da educação compensatória por acreditar que a origem do problema está nos aspectos socioculturais e; 5) inatismo/mbientalismo, interacionismo/construtivismo ("criança imatura"), procede-se a aplicação de provas para avaliar o desenvolvimento e a capacidade da criança, bem como as condições do ambiente, partindo da crença de que a origem do problema está no processo de desenvolvimento do indivíduo em contato com o meio adequado (Meira, 2003)

Observa-se no conteúdo das leis que regulamentam a atuação do psicólogo na rede pública de Educação a existência de concepções tradicionais e contemporâneas em Psicologia Escolar, sendo verificadas em uma mesma lei concepções distintas, em função das atividades atribuídas ao profissional de Psicologia.

Quanto às atividades presentes nos projetos, "avaliar alunos com dificuldades de aprendizagem, através da testagem e recursos apropriados, emitindo parecer psicológico e propondo encaminhamentos quando necessário" e a "realização de psicoterapia individual e/ou grupal", pode-se pensar que estas atribuições revelam uma concepção semelhante à teoria do dom ou aptidões individuais, na qual através de testes de aptidão e personalidade, busca-se na criança a origem dos problemas de aprendizagem. Já as atribuições "realizar visitas domiciliares" e "realizar orientação familiar" nos remete a concepção ambientalista, que parte da crença de que o ambiente familiar desajustado e os relacionamentos da criança são os determinantes dos problemas escolares.

Por outro lado, atribuições como: "colaborar na reconstrução e avaliação das práticas educacionais, visando favorecer a aprendizagem e o desenvolvimento psicossocial dos alunos" e "participar do trabalho de elaboração, implantação, avaliação e reformulação de projetos pedagógicos, currículo e políticas educacionais, concentrando sua ação nos aspectos que dizem respeito aos processos de desen- 
volvimento humano, de aprendizagem e das relações interpessoais" nos remete às teorias críticas contemporâneas, as quais se preocupam com as práticas educacionais e as relações estabelecidas no ambiente escolar enquanto produtores do fracasso escolar, deixando de focar o sujeito e seu contexto social como fatores determinantes das dificuldades de aprendizagem.

As teorias críticas entendem a queixa escolar como uma síntese de múltiplas determinações, incluindo relações familiares, grupos de amigos, contexto social e escolar, sendo que a superação das condições produtoras da queixa dependem da ação conjunta dos envolvidos, que pode ser mediada pelo psicólogo. Essa compreensão não visa desfocar a criança para culpabilizar a família ou a escola, mas se dirige às circunstâncias em que o processo educativo se realiza, entendendo que podem ser modificadas. O desafio da intervenção consiste em identificar possibilidades concretas para superação dessa situação (Tanamachi \& Meira, 2003).

Neste estudo, pode-se perceber que o trabalho do psicólogo escolar não é devidamente previsto pela legislação que regulamenta sua prática. Da mesma forma, supõe-se que as práticas desenvolvidas por muitos profissionais de Psicologia não condizem com as expectativas da gestão educacional, levando em conta que não existem especificações para sua atuação.

A atuação da Psicologia no contexto educacional visa contribuir para que a escola cumpra sua função social - de socializar o conhecimento acumulado historicamente e contribuir para a formação ética e política dos sujeitos -, não se restringindo à resolução de problemas e divulgação de teorias e conhecimentos psicológicos, mas atuando dentro de seus limites e especificidades, ajudando a escola a eliminar os obstáculos que se colocam entre os sujeitos e o conhecimento, auxiliando no processo de formação de práticas educativas que favoreçam os processos de humanização e desenvolvimento do pensamento crítico (Tanamachi \& Meira, 2003).

Essa atuação poderia ser efetivada com maior rigor se fossem elaboradas diretrizes e parâmetros para os projetos de lei, pautadas pelas evoluções da Psicologia Escolar crítica, mediante a participação de profissionais de Psicologia e Educação, os principais envolvidos nesta prática.

Nesse sentido, para que a Psicologia possa contribuir com a Educação é necessário que sejam construídas metodologias de trabalho baseadas em um movimento de ação/ reflexão/ação, permitindo que todos os envolvidos possam refletir sobre a própria prática social, utilizando-se de teorias que direcionem estas práticas, agindo de forma diferenciada e comprometida com o desenvolvimento de ações que traduzam essa nova compreensão crítica sobre si mesmo e sobre a realidade social (Tanamachi \& Meira, 2003).

\section{Conclusão}

A realização deste estudo apontou algumas particularidades da rede pública de Educação do Estado de Santa Catarina quanto ao processo de inserção do psicólogo na escola, especialmente no que diz respeito à regulamentação deste trabalho, sendo identificado um número restrito de municípios que possuem suas práticas legalmente previstas.

Além disso, a análise destes documentos e organização dos dados permitiu a explicitação de algumas inquietações que nos ocorreram, embora uma análise rigorosa, exigiria um exame mais detalhado destas produções.

Considerando a legislação que regulamenta e legitima o trabalho do psicólogo escolar, a qual não contempla a amplitude de atividades que podem ser desenvolvidas por este profissional e que existe uma variedade de concepções teóricas que perpassam as práticas previstas pela legislação, supõe-se que estes projetos de lei sejam resultado de processos distintos de elaboração.

Além disso, identifica-se a coexistência de concepções distintas de Psicologia Escolar no bojo de cada projeto de lei, abarcando concepções tradicionais e contemporâneas, o que nos leva a crer que não houve a participação do psicólogo na elaboração destes textos, o qual supostamente teria conhecimentos sobre os avanços das concepções em Psicologia Escolar crítica. Se houve, eles não estão apropriados destas discussões.

Dessa forma, sugere-se para futuras pesquisas a investigação sobre os processos de elaboração dos projetos de lei, a fim de responder aos seguintes questionamentos: quem participa do processo de elaboração dos projetos de lei que inserem o psicólogo na escola? O psicólogo participa da elaboração da lei que regulamenta sua atuação? Como são definidas as especificações do cargo de psicólogo escolar? As práticas desenvolvidas condizem com as atividades previstas em lei?

Também é evidente a necessidade de refletir sobre a formação acadêmica e a formação continuada. Assim, questiona-se: como está o ensino de Psicologia e Educação nos cursos de graduação? Como tem sido trabalhada a formação continuada dos psicólogos escolares e educacionais? Que políticas são previstas para uma formação em serviço que dê conta do profissional lidar com a realidade escolar?

Estes e tantos outros questionamentos são oriundos dos resultados desta investigação, porém, as respostas a estas questões exigem a realização de novas pesquisas, o que enriqueceria os resultados deste estudo.

Espera-se que esta pesquisa tenha contribuído com elementos que favoreçam o debate e o estudo sobre a inserção do psicólogo na rede pública de Educação, contribuindo com a discussão que tem se dado no âmbito das entidades científicas e profissionais da Psicologia. 


\section{Referências}

Antunes, M. A. M. (2003). Psicologia e Educação no Brasil: um olhar histórico-crítico. Em M. E. Meira \& M. A. Antunes (Orgs.), Psicologia Escolar: teorias críticas (pp. 139-168). São Paulo: Casa do Psicólogo.

Conselho Regional de Psicologia de Santa Catarina - $12^{\mathrm{a}}$ Região - CRP-12. (2007). Comissão de Educação. Relatório do levantamento sobre projetos de lei e práticas de psicólogos na área de Educação. Florianópolis: CRP-12.

Flick, U. (2004). Uma introdução à pesquisa qualitativa. Porto Alegre: Bookman.

Hüning, S. M., \& Guareschi, N. F. (2005). O que estamos construindo: especialidades ou especialismos?. Psicologia \& Sociedade, 17(1), 17-28.

Lima, A. O. (2005). Breve histórico da Psicologia Escolar no Brasil. Psicologia Argumento, 23(42), 17-23.
Meira, M. E. M. (2003). Construindo uma concepção crítica de psicologia escolar: contribuições da pedagogia histórico-crítica e da psicologia sócio-histórica. Em M. E. M. Meira \& M. A. M. Antunes (Orgs.), Psicologia Escolar: teorias críticas (pp. 13-78). São Paulo: Casa do Psicólogo.

Meira, M. E. M, \& Antunes, M. A. (Orgs.). (2003). Psicologia escolar: teorias críticas. São Paulo: Casa do Psicólogo.

Patto, M. H. (1987). Psicologia e ideologia: uma introdução crítica à Psicologia Escolar. São Paulo: T. A. Queiroz.

Tanamachi, E. R., \& Meira, M. E. M. (2003). A atuação do psicólogo como expressão do pensamento crítico em psicologia e educação. Em M. E. Meira \& M. A. Antunes (Orgs.), Psicologia escolar: práticas críticas (pp. 11-62). São Paulo: Casa do Psicólogo.

Yazlle, E. G. (1997). Atuação do psicólogo escolar: alguns dados históricos. Em B. B. Cunha (Org.), Psicologia na escola: um pouco de história e alguns histórias (pp. 11-38). São Paulo: Arte \& Ciência.

\section{Sobre os autores}

Celso Francisco Tondin (tondin@unochapeco.edu.br)

Universidade Comunitária Regional de Chapecó, Chapecó - SC

Débora Dedonatti (debo@unochapeco.edu.br)

Universidade Comunitária Regional de Chapecó, Chapecó - SC

Irme Salete Bonamigo (bonamigo@unochapeco.edu.br)

Universidade Comunitária Regional de Chapecó, Chapecó - SC

\section{Correspondência}

Celso Francisco Tondin

Rua Uruguai, 333-E ap. 104

Centro, Chapecó - SC CEP: 89.801-570

\section{Agradecimentos}

Fundo de Amparo à Pesquisa da Universidade Comunitária Regional de Chapecó (Unochapecó) 